\title{
Expression of endothelial nitric oxide synthase correlates with the angiogenic phenotype of and predicts poor prognosis in human gastric cancer
}

\author{
Liwei Wang*1, Gary G. Shi*1, James C. Yao ${ }^{1}$, Weida Gong ${ }^{2}$, Daoyan Wei ${ }^{1}$, Tsung-Teh Wu², Jaffer A. Ajani ${ }^{1}$, \\ SuYun HuAng ${ }^{2,4}$, and KePING XIE ${ }^{1,4}$ \\ ${ }^{1}$ Department of Gastrointestinal Medical Oncology, Unit 426, The University of Texas M. D. Anderson Cancer Center, 1515 Holcombe \\ Boulevard, Houston, TX 77030, USA \\ ${ }^{2}$ Department of Neurosurgery, The University of Texas M. D. Anderson Cancer Center, Houston, TX, USA \\ ${ }^{3}$ Department of Pathology, The University of Texas M. D. Anderson Cancer Center, Houston, TX, USA \\ ${ }^{4}$ Department of Cancer Biology, The University of Texas M. D. Anderson Cancer Center, Houston, TX, USA
}

\begin{abstract}
Background. Angiogenesis is a critical aspect of cancer biology and is subject to regulation by multiple molecular pathways. We evaluated the expression of nitric oxide synthase (NOS) III and its relationship with the angiogenic phenotype and expression of the transcription factor Sp1, as well as their effect on survival in patients with gastric cancer.

Methods. The NOS III expression level and tumor microvessel density (MVD) status were determined via immunohistochemistry, using archived tissue specimens from 86 resected gastric cancer cases; these findings were then correlated with Sp1 expression and clinicopathological features.

Results. NOS III protein expression was significantly higher in both primary tumors and lymph node metastases than in normal gastric mucosa. In primary tumors, NOS III expression correlated highly with $\mathrm{Sp1}$ expression $(P=0.001)$ and MVD status $(P=0.001)$. Patients with strong Sp1 expression were more likely to have strong NOS III expression (15 times) and a high MVD (7 times) than were those with negative Sp1 expression. In univariate survival analyses, strong NOS III expression $(P=0.042)$, strong Sp1 expression $(P=0.007)$, and a high MVD $(P=0.036)$ were associated with worse survival. However, when patients' NOS III and Sp1 expression levels, MVD status, disease stage, completeness of resection, Lauren's classification, and age were entered in a Cox proportional hazards model, only strong NOS III ( $P$ $=0.019)$ and Sp1 expression $(P=0.029)$ and advanced disease stage $(P=0.006)$ were independently prognostic of poor survival.

Conclusion. Our results indicated that the expression of NOS III, a potential downstream effector of $\mathrm{Sp1}$, may play an important role in tumor angiogenesis and aggressiveness in gastric cancer.
\end{abstract}

Offprint requests to: $\mathrm{K}$. Xie

* These authors contributed equally to this work.

Received: August 19, 2004 / Accepted: October 26, 2004
Key words Transcription factor $\mathrm{Sp} 1 \cdot$ Angiogenesis $\cdot$ Metastasis $\cdot$ Tumor $\cdot$ Prognosis

\section{Introduction}

Endothelial nitric oxide synthase (NOS; eNOS, or NOS III), a $\mathrm{Ca}^{2+}$-dependent isoform that was first found in vascular endothelial cells, oxidizes L-arginine to generate L-citrulline and NO [1,2]. Expression of NOS III has been found in other types of cells, such as airway epithelial, neuronal, and certain tumor cells [3-5]. It has been shown that NO generated by NOS III regulates blood pressure, platelet aggregation, leukocyte adherence, and vascular smooth muscle cell mitogenesis and angiogenesis [6-8]. For example, NO increases angiogenesis in ischemic murine tissues [9], while NOS III inhibitors impair angiogenesis in granulation tissue during gastric ulcer healing $[10,11]$. NO is also vital to the activity of proangiogenic cytokines, such as vascular endothelial growth factor [12-14]. Concerning tumor angiogenesis, many studies have suggested that sustained NO production at a low level in solid tumors can sustain tumor growth through enhanced vascular permeability, increased blood flow, and increased vascularization due to stimulation of endothelial cell growth and migration $[12,15,16]$. NO may mediate these angiogenic processes predominantly via NOS III activation $[12,15,16]$. Along with these findings, irregular NOS III expression by tumor cells has been linked with increased tumor angiogenesis and metastasis $[8,12,17]$.

Increased NOS III expression has been noted in the vasculature of various tumor tissues when compared with that in normal and nontumorigenic tissue samples, including breast [18], bladder [19], colorectal [20,21], brain [22], and pancreatic [23] cancers, while expression 
of NOS III and its potential roles in human gastric cancer remain unclear [24,25]. Aberrant expression of NOS III has also been noted in certain tumor cells, such as colon adenocarcinoma and astrocytoma cells [3$5,26]$. However, the mechanisms for aberrant NOS III expression in tumor cells and tumor-associated endothelial cells are largely unknown. Regulation of NOS III expression can occur in a transcriptional, posttranscriptional, and posttranslational manner [3-5,27]. Increasing evidence suggests that NOS III expression, although constitutive, can be regulated by various hormones, cytokines, and growth factors, and by genetic alterations, such as oncogene activation and tumor suppressor inactivation [3-5,27]. Significantly, many tumors often exhibit aberrant expression of these factors and genetic alterations, and these molecular changes often transmit signals through Sp1, which is critical to NOS III expression [5,28-31]. Therefore, we hypothesize that Sp1 activation is a common signaling intermediate leading to altered NOS III expression in tumors.

$\mathrm{Sp} 1$ is a sequence-specific DNA-binding protein that is important to the transcription of many cellular and viral genes that contain GC boxes in their promoter. Additional transcription factors similar to $\mathrm{Sp} 1$ in their structural and transcriptional properties ( $\mathrm{Sp} 2, \mathrm{Sp} 3$, and Sp4) have been cloned, resulting in the formation of an $\mathrm{Sp} 1$ multigene family $[32,33]$. Because $\mathrm{Sp} 1$ is a critical transcription factor for many genes that are key to the regulation of multiple aspects of tumor biology, abnormal Sp1 expression and activation may contribute to gastric cancer development and progression. Among other lines of evidence supporting this notion [34-36], we recently showed that $\mathrm{Sp} 1$ is overactivated in human gastric cancer [37] and pancreatic cancer [38]. In addition, expression of $\mathrm{Sp} 1$ predicts survival in gastric cancer patients [37]. However, it is unknown whether Sp1 overactivation confers an elevated angiogenic phenotype to gastric cancer cells, at least in part through elevated NOS III expression and activation.

In the present study, we examined the expression of NOS III and its relationship with the angiogenic phenotype of and Sp1 expression in tissue specimens obtained from patients with resected gastric cancer and their impact on the patients' survival duration. We found that NOS III overexpression, most likely through abnormal Sp1 activation, contributed directly to tumor angiogenesis and the overall aggressive biology of gastric cancer, and that these two entities are potential molecular markers for poor prognosis in gastric cancer.

\section{Patients, materials, and methods}

\section{Human tissue specimens and patient information}

We used human gastric cancer tissue specimens preserved in the Gastric Cancer Tissue Bank, and we obtained information about the patients from the bank's comprehensive database at The University of Texas M. D. Anderson Cancer Center. Primary gastric cancer in these patients was diagnosed and treated at M. D. Anderson Cancer Center from 1985 to 1998. The patients had a well-documented clinical history and follow-up information. None of them underwent preoperative chemotherapy and/or radiation therapy. Eightysix cases were selected to represent all of the stages and histological types of malignant gastric cancer for this study. All of the patients had undergone gastrectomy with lymph node dissection. All of them were also observed at M. D. Anderson through the end of 1999. The median follow-up duration was 25.7 months. At the last follow-up examination, 30 patients were still alive, while 56 patients had died. Tissue specimens from 86 primary tumors, 53 lymph node metastases, and 57 normal gastric tissues obtained from patients without gastric cancer were included in this study. The patients consisted of 56 men and 30 women, and their mean age was 62 years. Proximal cancer localization was observed in 20 cases. Fifty-three patients had an intestinal-type Lauren's histological classification, while 33 had a diffuse-type classification. Details of the patient characteristics are provided in Table 1.

\section{Immunohistochemistry}

Sections (5- $\mu \mathrm{m}$-thick) of formalin-fixed, paraffinembedded tumor specimens were deparaffinized in xylene and rehydrated in graded alcohol. Antigen retrieval was performed with $0.05 \%$ saponin for $30 \mathrm{~min}$ at room temperature. Endogenous peroxidase was blocked using $3 \%$ hydrogen peroxide in phosphate-buffered saline (PBS) for $12 \mathrm{~min}$. The specimens were incubated with a protein-blocking solution, consisting of PBS ( $\mathrm{pH} 7.5)$ containing 5\% normal horse serum and $1 \%$ normal goat serum, for $20 \mathrm{~min}$ at room temperature and then incubated at $4{ }^{\circ} \mathrm{C}$ in a $1: 200$ dilution of a rabbit polyclonal antibody against human Sp1 (clone PEP2) or a 1:100 dilution of a rabbit polyclonal antibody against human NOS III (Santa Cruz Biotechnology, Santa Cruz, CA, USA). The samples were then rinsed and incubated with peroxidase-conjugated anti-rabbit IgG for $1 \mathrm{~h}$ at room temperature. Next, the slides were rinsed with PBS and incubated for $5 \mathrm{~min}$ with diaminobenzidine (Research Genetics, Huntsville, AL, USA). The sections were washed three times with distilled water, counterstained with Mayer's hematoxylin (Biogenex Laboratories, San 
Table 1. Patient characteristics and NOS III expression in 86 patients with resected $\underline{\text { gastric cancer }}$

\begin{tabular}{|c|c|c|c|c|c|}
\hline \multirow[b]{3}{*}{ Parameter } & \multicolumn{4}{|c|}{ Number of patients } & \multirow[b]{3}{*}{$P$ value } \\
\hline & \multirow[b]{2}{*}{ All } & \multicolumn{3}{|c|}{ NOS III expression } & \\
\hline & & Negative & Weak & Strong & \\
\hline \multicolumn{6}{|l|}{ Sex } \\
\hline Male & 56 & 10 & 31 & 15 & \multirow[t]{2}{*}{ NS } \\
\hline Female & 30 & 11 & 15 & 4 & \\
\hline $\begin{array}{l}\text { Age, years } \\
\text { Mean (SD) }\end{array}$ & $62(14)$ & $65(12)$ & $59(15)$ & $65(12)$ & NS \\
\hline \multicolumn{6}{|l|}{ AJCC stage } \\
\hline I & 14 & 3 & 6 & 5 & \multirow[t]{4}{*}{ NS } \\
\hline II & 28 & 11 & 11 & 6 & \\
\hline III & 30 & 3 & 22 & 5 & \\
\hline IV & 14 & 4 & 7 & 3 & \\
\hline \multicolumn{6}{|c|}{ Completeness of resection } \\
\hline R0 & 69 & 17 & 37 & 15 & \multirow[t]{2}{*}{ NS } \\
\hline R1, R2 & 17 & 4 & 9 & 4 & \\
\hline \multicolumn{6}{|l|}{ Pathology type } \\
\hline Papillary & 12 & 4 & 5 & 3 & \multirow[t]{6}{*}{ NS } \\
\hline Tubular & 28 & 6 & 13 & 9 & \\
\hline Diffuse & 8 & 2 & 5 & 1 & \\
\hline Mucinous & 5 & 2 & 2 & 1 & \\
\hline Signet ring & 21 & 5 & 14 & 2 & \\
\hline Mixed & 12 & 2 & 7 & 3 & \\
\hline \multicolumn{6}{|c|}{ Lauren's histology } \\
\hline Intestinal & 53 & 13 & 27 & 13 & \multirow[t]{2}{*}{ NS } \\
\hline Diffuse & 33 & 8 & 19 & 6 & \\
\hline
\end{tabular}

Pearson's $\chi^{2}$ test was performed to determine the statistical significance of the relationships of NOS III expression with various parameters

Ramon, CA, USA), and washed once each with distilled water and PBS. Afterward, the slides were mounted using a Universal Mount (Research Genetics) and examined using a bright-field microscope. A positive reaction was indicated by a reddish-brown precipitate in the nuclei (Sp1) or cytoplasm (NOS III) $[25,26]$. Depending on the percentage of positive cells and staining intensity, Sp1 and NOS III stainings were classified into three groups: negative, weak, and strong expression. Specifically, the percentage of positive cells was divided into five grades (percentage scores): $0(<10 \%), 1(10 \%-$ $25 \%), 2(26 \%-50 \%), 3(51 \%-75 \%)$, and $4(>75 \%)$. The staining intensity was divided into four grades (intensity scores): 0 (no staining), 1 (light brown), 2 (brown), and 3 (dark brown). Sp1 staining positivity was determined using the following formula: overall score $=$ percentage score . intensity score. Overall scores of $\leq 3,>3-\leq 6$, and $>6$ were defined as negative, weak, and strong expression, respectively [37].

\section{Western blot analysis}

Whole-cell lysates were prepared from human normal and gastric cancer tissue specimens. Four paired normal gastric and gastric tumor tissue specimens were selected from the patients with known expression levels of Sp1 and NOS III, as confirmed by immunostaining, with the tissue specimens showing similar percentages of tumor epithelial cells present relative to stroma. Standard Western blotting was performed using a polyclonal rabbit antibody against human Sp1 (clone PEP2; Santa Cruz Biotechnology); a polyclonal rabbit antibody against human NOS III; and anti-rabbit IgG, a horseradish peroxidase-linked $\mathrm{F}\left(\mathrm{ab}^{\prime}\right)_{2}$ fragment obtained from a donkey (Amersham Life Sciences, Arlington Heights, IL, USA). Equal protein-sample loading was monitored by incubating the same membrane filter with an anti- $\beta$-actin antibody [37]. The probe proteins were detected using the Amersham enhanced chemiluminescence system according to the manufacturer's instructions.

Quantification of tumor microvessel density (MVD)

For CD34 staining, tissue sections were processed and stained with a 1:100 dilution of a monoclonal goat anti-CD34 antibody (PECAM1-M20; Santa Cruz Biotechnology) and peroxidase-conjugated anti-goat $\operatorname{IgG}$ 
and then counterstained with Mayer's hematoxylin (Biogenex Laboratories). The slides were mounted with the sections and examined using a bright-field microscope. A positive reaction was indicated by a reddishbrown precipitate in the cytoplasm. For quantification of tumor MVD, the vessels on each section were counted in five high-power fields $(\times 200$ magnification $[\times 20$ objective, $\times 10$ ocular]). The MVD levels were divided into three groups: low $(<50)$, moderate (50-100), and high (>100), as described previously [37].

\section{Statistical analysis}

The two-tailed $\chi^{2}$ test was performed to determine the significance of the difference between the covariates. Survival durations were calculated using the KaplanMeier method. The log-rank test was used to compare the cumulative survival durations in the patient groups. Also, the Cox proportional hazards model was used to compute univariate and multivariate hazards ratios for the study parameters. The patients' levels of Sp1 and NOS III expression, MVD, age, sex, Lauren's histological classification, disease stage American Joint Committee on Cancer (AJCC), and completeness of surgical resection (R0 versus $\mathrm{R} 1$ and $\mathrm{R} 2$ ) were included in the model. In all of the tests, a $P$ value less than 0.05 was defined as statistically significant. The SPSS software program (version 11.05; SPSS, Chicago, IL, USA) was used for the analyses.

\section{Results}

NOS III expression in normal human gastric mucosa, tumor tissue, and metastatic lymph nodes

NOS III expression was evaluated in the primary tumor tissue of all 86 patients via immunohistochemistry. NOS III expression was classified as strong, weak, and negative in $21(24 \%), 46(54 \%)$, and $19(22 \%)$ cases, respectively (Table 1). No significant differences in the distribution of the patients according to sex, race/ ethnicity, tumor location, type of resection, residual disease status, extent of lymphadenectomy, or Lauren's histological classification were detected in the three NOS III expression categories. When NOS III expression was compared among normal mucosa, primary tumors, and metastatic lymph nodes, there was significantly higher NOS III expression in both primary tumors and metastatic lymph nodes than in normal gastric mucosa (Fig. 1). The samples with known NOS III expression were further selected for confirmation of NOS III protein expression, using Western blot analysis. As shown in Fig. 2, NOS III protein expression was higher in primary tumors than in normal mucosa.

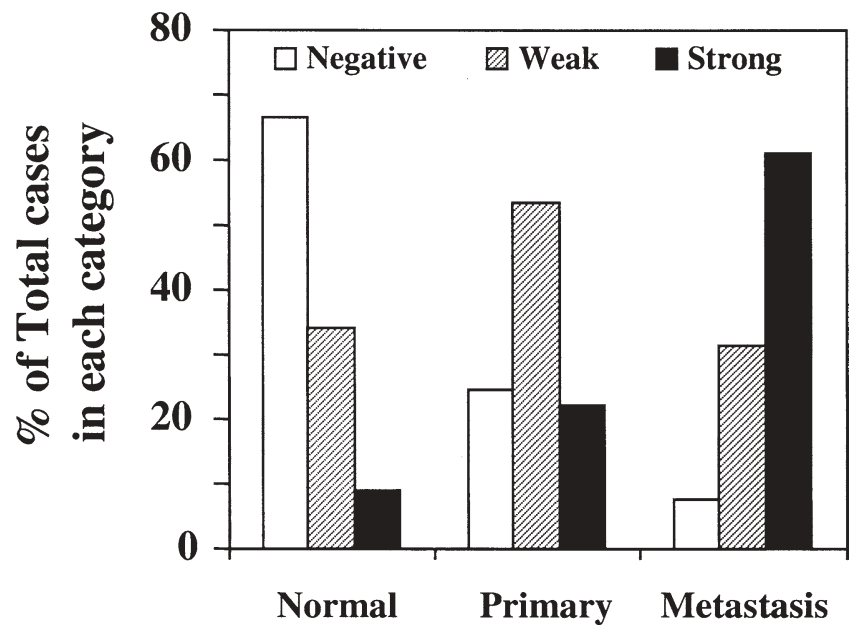

Fig. 1. Nitric oxide synthase (NOS III) protein expression in human normal gastric mucosa, primary gastric cancer, and metastatic lymph nodes. Immunohistochemical staining was performed, using a specific anti-NOS III antibody, on the tissue sections of 86 gastric cancer, 53 metastatic lymph node, and 57 normal human gastric tissue specimens. Overall, lymph node metastasis specimens exhibited the highest level of NOS III expression $(P<0.001)$, and tumor tissue specimens had a much higher level of NOS III expression than adjacent normal tissue specimens did $(P<0.001)$
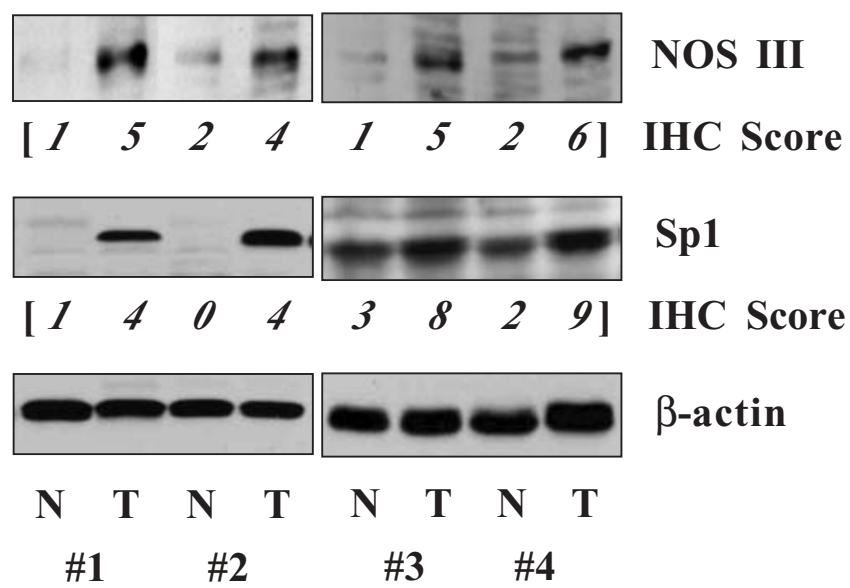

Fig. 2. NOS III and Sp1 protein expression in human gastric cancer tissue. Whole-cell protein extracts were prepared from four paired normal gastric $(N)$ and gastric tumor tissue $(T)$ specimens obtained from the patients with NOS III and Sp1 expression detected via immunostaining (immunohistochemical $[I H C]$ scores in italics). The level of expression of NOS III and Sp1 protein was determined, using Western blot analysis, with $10-\mu \mathrm{g}$ whole-cell protein extracts. Equal protein-sample loading was monitored by hybridizing the same membrane filter with an anti- $\beta$-actin antibody. The level of both NOS III and $\mathrm{Sp} 1$ protein expression was significantly elevated in tumor tissue compared with that in normal tissue 
Table 2. Correlation of NOS III expression, Sp1 expression, and MVD status in primary gastric cancer ${ }^{\mathrm{a}}$

\begin{tabular}{|c|c|c|c|c|}
\hline & \multicolumn{3}{|c|}{ NOS III status } & \multirow[b]{2}{*}{$P$ value } \\
\hline & Negative & Weak & Strong & \\
\hline \multicolumn{5}{|c|}{ Sp1 expression } \\
\hline Negative & 9 & 7 & 1 & 0.001 \\
\hline Weak & 9 & 31 & 8 & - \\
\hline Strong & 3 & 8 & 10 & - \\
\hline \multicolumn{5}{|l|}{ MVD status } \\
\hline Low & 2 & 7 & 1 & 0.001 \\
\hline Moderate & 16 & 25 & 4 & - \\
\hline High & 3 & 14 & 14 & - \\
\hline
\end{tabular}

\section{Association of NOS III expression with Sp1 expression and $M V D$}

Next, we determined the relationship between NOS III and $\mathrm{Sp} 1$ expression, as described previously [37]. NOS III expression was highly correlated with Sp1 expression $(P=0.001)$. Similarly, NOS III expression was significantly correlated with the tumor MVD $(P=$ 0.001 ; Table 2). These findings were further confirmed via analysis of consecutive sections, in which we found that the pattern of NOS III expression was consistent with that of $\mathrm{Sp} 1$ expression and the tumor MVD (Fig. 3). These data provided clinical evidence supporting our hypothesis that aberrant Sp1 activation causes increased angiogenesis through the overexpression of various angiogenic molecules, such as NOS III.

To further test the association of NOS III expression with $\mathrm{Sp} 1$ expression and MVD status, we performed an ordinal logistic regression analysis, in which MVD status or $\mathrm{Sp} 1$ expression was the response variable, with three levels as we described previously (coded 0 for low, 1 for moderate, and 2 for high MVD; and 0 for negative, 1 for weak, and 2 for strong Sp1 expression) [37]. Table 3 shows that patients with gastric cancer who had a strong level of NOS III expression were 15 times more likely to have strong Sp1 expression when compared with those who had negative NOS III expression, a difference which was statistically significant $(P=0.017)$. Similarly, patients with gastric cancer who had strong NOS III expression were seven times more likely to have a high MVD when compared with those who had weak NOS III expression $(P=0.027)$. These results suggest critical roles for NOS III and Sp1 in tumor angiogenesis.

\section{Effect of NOS III expression on patient survival}

The median survival durations in patients who had a tumor with negative, weak, and strong NOS III expres-
Table 3. Odds ratios of strong NOS III expression according to $\mathrm{Sp} 1$ expression and MVD status ${ }^{\mathrm{a}}$

\begin{tabular}{lcc}
\hline & Odds ratio (95\% CI) & $P$ value \\
\hline Sp1 expression & & \\
$\quad$ Negative & 1.0 (Referent) & - \\
Weak & $3.2(0.4-27.7)$ & 0.291 \\
$\quad$ Strong & $14.5(1.6-130.4)$ & 0.017 \\
MVD status & 1.0 (Referent) & - \\
$\quad$ Low & 0.9 (0.1-8.8) & 0.912 \\
Moderate & $7.4(0.8-65.8)$ & 0.027 \\
High &
\end{tabular}

${ }^{\mathrm{a}}$ Odds ratio of strong NOS III expression in the weak and strong Sp1 expression and moderate and high MVD groups compared with that in the negative Sp1 expression and low MVD groups

sion were 64, 24, and 7 months, respectively. Elevated NOS III expression was associated with an inferior survival duration $(P=0.042$; Table 4$)$. As reported previously, the impact of Sp1 expression $(P=0.007)$ and MVD status $(P=0.036)$ on survival duration was also statistically significant. Other parameters that affected survival in the univariate analyses included the AJCC stage $(P<0.001)$ and completeness of resection $(P=0.0002)$. Neither the patients' age at diagnosis (as a continuous variable according to the univariate Cox proportional hazards analysis) nor their Lauren's histological classification had a statistically significant effect on survival $(P=0.0605)$.

The patients' NOS III expression level, Sp1 expression level, MVD status, disease stage, completeness of resection, age, and Lauren's histological classification were entered into a Cox proportional hazards model for multivariate analysis (Table 5). Adjustments for the effect of covariates, strong NOS III expression $(P=$ $0.019)$, strong Sp1 expression $(P=0.029)$, and advanced disease stage $(P=0.006)$ were independent predictors of poor survival. The odds ratio in the group with strong NOS III expression (3.6; 95\% confidence interval [CI], 

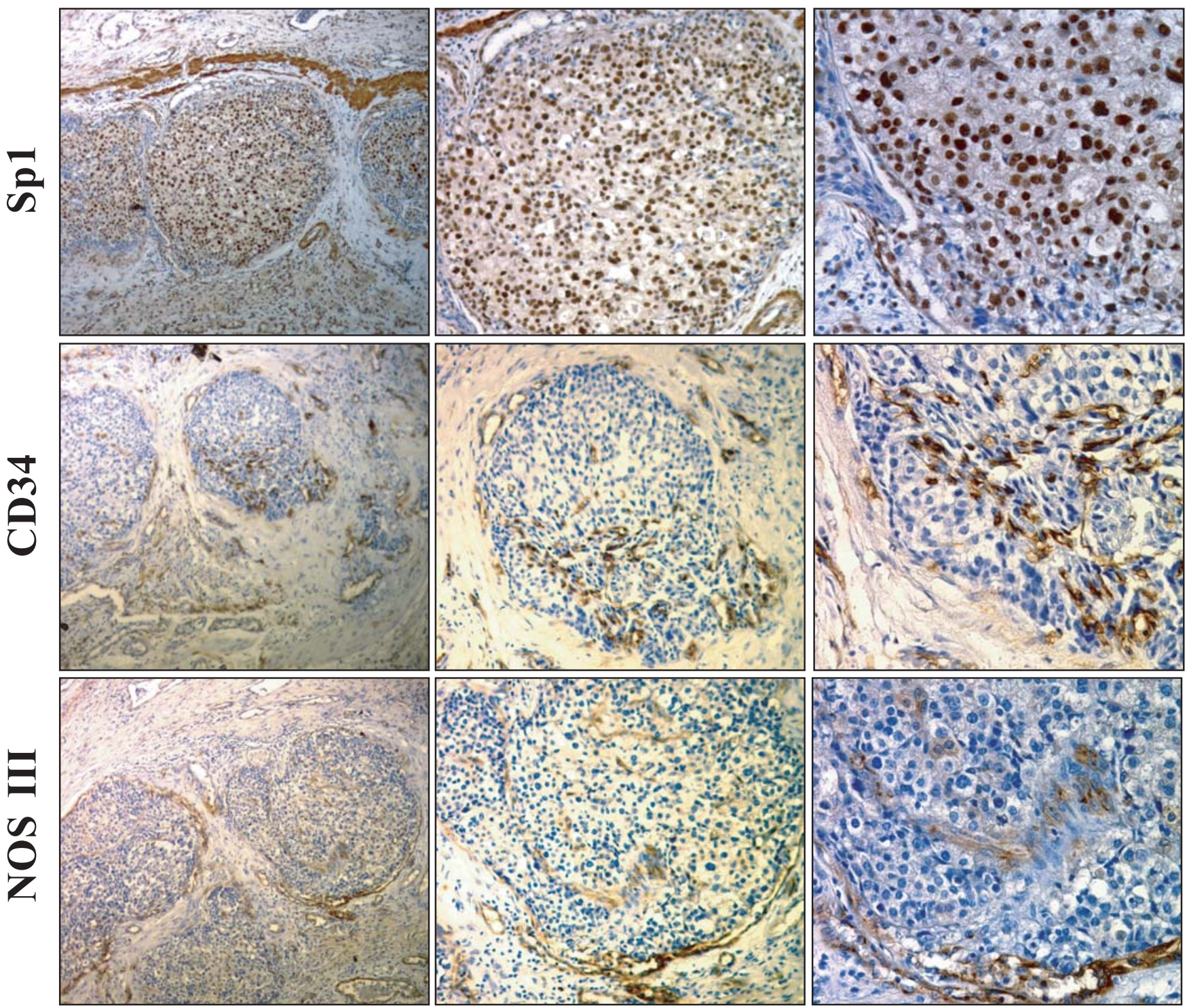

\section{$\times \mathbf{5 0}$}

$\times 100$

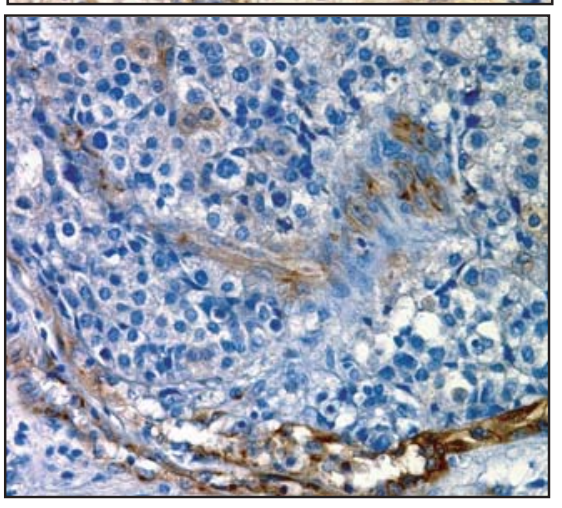

\section{$\times 200$}

Fig. 3. Localization of NOS III and Sp1 protein expression in human gastric cancer tissue. Tissue sections were prepared from formalin-fixed, paraffin-embedded gastric cancer specimens. Immunohistochemical staining was performed using specific antibodies against Sp1, CD34, and NOS III. The pictures were taken at different magnifications $(\times 50, \times 100$, and $\times 200)$. Of note is that strong Sp1 expression directly correlated with strong NOS III expression and high microvessel density (MVD) status

1.23-10.49) was significantly higher than that in the group with negative NOS III expression (referent). Additionally, there was a trend toward worse survival in patients with a high tumor MVD. The odds ratios in the groups with moderate and high tumor MVD were 1.1 and 1.6, respectively, which were higher than that in the group with a low tumor MVD. However, this difference was not statistically significant. Neither the patients' age at diagnosis, completeness of resection, nor Lauren's histological classification had a statistically significant effect on survival in the multivariate analyses.

\section{Discussion}

In the present study, we found that elevated NOS III expression in human gastric cancer was found predominantly in tumor vascular endothelial cells and coincided 
Table 4. Univariate survival analysis ${ }^{\mathrm{a}}$

\begin{tabular}{lcc}
\hline Parameter & Median survival (months) & $P$ value \\
\hline NOS III expression & 64 & 0.0420 \\
Negative & 24 & \\
Weak & 7 & 0.0070 \\
Strong & 44 & \\
Sp1 expression & 38 & 0.0360 \\
Negative & 8 & \\
Weak & & \\
Strong & 64 & $<0.0010$ \\
Tumor MVD status & 37 & \\
Low & 14 & \\
Moderate & & \\
High & 91 & 0.0002 \\
AJCC stage & 64 & \\
I & 23 & 0.0605 \\
II & 9 & 0.7010 \\
III & & \\
IV & 41 & \\
Completeness of resection & 11 & \\
R0 & & \\
R1, R2 & 41 & \\
Lauren's histology & 15 & \\
Intestinal & & \\
Diffuse & & \\
Age (continuous variable) & & \\
\hline
\end{tabular}

${ }^{a}$ Estimated using the Cox proportional hazards model

Table 5. Multivariate survival analysis ${ }^{\mathrm{a}}$

\begin{tabular}{|c|c|c|}
\hline Parameter & Multivariate odds ratio $(95 \% \mathrm{CI})$ & $P$ value \\
\hline \multicolumn{3}{|l|}{ NOS III expression } \\
\hline Negative & 1.0 (Referent) & \\
\hline Weak & $1.6(0.63-3.99)$ & 0.331 \\
\hline Strong & $3.6(1.23-10.49)$ & 0.019 \\
\hline \multicolumn{3}{|l|}{ Sp1 expression } \\
\hline Negative & 1.0 (Referent) & \\
\hline Weak & $1.5(0.62-3.75)$ & 0.352 \\
\hline Strong & $3.1(1.12-8.80)$ & 0.029 \\
\hline \multicolumn{3}{|l|}{ Tumor MVD status } \\
\hline Low & 1.0 (Referent) & \\
\hline Moderate & $1.1(0.40-2.76)$ & 0.917 \\
\hline High & $1.6(0.51-4.85)$ & 0.431 \\
\hline \multicolumn{3}{|l|}{ AJCC stage } \\
\hline I & 1.0 (Referent) & \\
\hline II & $2.3(0.65-8.16)$ & 0.200 \\
\hline III & $7.6(2.39-24.01)$ & 0.006 \\
\hline IV & $12.7(2.96-54.41)$ & 0.006 \\
\hline \multicolumn{3}{|l|}{ Completeness of resection } \\
\hline R0 & 1.0 (Referent) & \\
\hline $\mathrm{R} 1$ and $\mathrm{R} 2$ & $1.5(0.63-3.49)$ & 0.375 \\
\hline \multicolumn{3}{|l|}{ Lauren's histology } \\
\hline Intestinal & 1.0 (Referent) & \\
\hline Diffuse & $1.6(0.66-3.99)$ & 0.297 \\
\hline Age (continuous variable) & $1.0(0.97-1.00)$ & 0.859 \\
\hline
\end{tabular}


with Sp1 overexpression predominantly in tumor epithelial cells. The NOS III expression level was directly correlated with the tumor MVD status and inversely correlated with patient survival. In a multivariate analysis, strong NOS III and Sp1 expressions were independent predictors of poor survival, while tumor MVD was not.

Previous studies have documented NOS III expression in human gastric cancer $[24,25]$. Although NOS III protein expression has been observed in both epithelial and vascular endothelial cells in tumor tissue samples, including those from breast [18,39], bladder [19,40,41], colorectal [20,42], brain [22,43,44], and pancreatic [23] cancers, we found that it was predominantly localized in the vasculature of gastric cancer tissue. This is consistent with previous findings in gastric tumor tissue samples [24,25]. The potential roles of NOS III in human cancer development and progression are unknown in gastric cancer and quite controversial in other types of cancer [18-24,39-44]. For example, in human breast cancer, NOS III appears to be expressed in tumor epithelial cells, and its presence is negatively correlated with histological grade and lymph node status [18]; however, others have found that NOS III protein expression is restricted to vascular endothelial cells in all tumor specimens, without a significant difference from that in normal tissues and with no correlation with the tumor grade [39]. In human supratentorial astrocytic tumors, astrocytic tumor vessels possess higher NOS III activity, resulting in NO production, than do normal vessels, and expression of NOS III is significantly correlated with histological grade and proliferative potential [22]. In oligodendrogliomas, however, there is sparse expression of NOS III in tumor cells, but rich expression of it in vascular endothelial cells in both the tumor and surrounding tissue, independent of tumor grade [43]. This finding in patients with oligodendroglioma is consistent with recent findings showing that NOS III is expressed sporadically in tumor cells but expressed at a higher level in vascular endothelial cells in the tumor itself, peritumoral area, and metastases in patients with a glial neoplasm; this expression does not indicate brain tumor differentiation or malignancy, however [44].

In gastric cancer, the initial studies using immunohistochemical staining found a marked reduction of NOS III expression in tumor tissue as compared with that in normal tissue $[24,45]$, although a recent study using Western blot analysis did not find a significant difference in NOS III expression between normal gastric mucosa and gastric cancer [25]. In the present study, NOS III expression was higher in gastric cancer tissues than in normal tissues in Western blot analysis. This was confirmed via immunostaining. In addition, NOS III expression in the areas of high MVD (i.e., "hot spots") was uniformly higher than that in normal tissues. The apparent discrepancy between our study and previous reports may be due to multiple factors. One possibility is the methods used for detecting NOS III expression. NOS III expression is highly heterogeneous in tumor tissues. NOS activity measurement and NOS III immunoblotting may only reflect the overall NOS III expression in tumor tissues. In addition, the tumor tissues and sample sizes of tissue specimens selected may have contributed to the inconsistent results. For example, we noticed increased NOS III expression in "normal" gastric mucosa that was evidently inflamed (data not shown). The ratios between tumor epithelium and stroma can also affect the overall NOS III expression level. These factors can be easily overlooked when the collected tissue samples are grounded for NOS III activity measurement and immunoblotting. In our study, all of the samples used for Western blot analysis were confirmed via histology, and only samples with similar ratios of tumor epithelium versus stroma and without significant inflammation were used.

Although NOS III expression has been implicated in tumor biology, its impact is unknown in gastric cancer. While NOS III protein expression was detected in all gastric cancer specimens and was not different from that in normal gastric mucosa, the quantity of NOS III in gastric cancer tissues appeared to be negatively correlated with serosal invasion [25]. Other reports have suggested that the level of NOS III expression is not associated with the disease stage [45]. In the present study, we did not find a significant association between NOS III expression and disease stage. However, we did find a highly significant negative correlation between NOS III expression and patient survival. This may reflect the role of NOS III in the regulation of vascular structure and function. Specifically, NO produced by NOS III may increase tumor blood-vessel formation (angiogenesis) and vessel dilatation, thus increasing the blood supply to the tumor $[8,12,15-17]$. This is consistent with the results of several experimental studies $[17,46,47]$. Our studies thus provide supportive evidence that increased NOS III expression and NO production can contribute to gastric cancer development and progression.

Angiogenesis is essential for tumor growth and metastasis [48] and has been considered the most important prognostic indicator for predicting overall survival [49]. Numerous lines of evidence have shown that tumor angiogenesis, as quantitated according to the MVD, plays a significant clinicopathological role in patients with several types of tumors [50-54]. However, the clinicopathological role of MVD in gastric cancer development and progression remains largely unclear. MVD does serve as an indicator of poor prognosis [55,56]. Specifically, a high MVD is significantly and positively associated with deep tumor invasion and dis- 
tant metastasis. Moreover, the overall survival duration in patients with a high MVD has been found to be significantly lower than that in patients with a low MVD [56-59]. In addition, a recent study demonstrated a statistically significant correlation between MVD and the two main histological parameters: tumor grade and histological type according to the Lauren's classification. In well- and moderately differentiated tumors, the MVD has been shown to be significantly lower than that in poorly differentiated tumors. Also, the MVD has been shown to be higher in diffuse-type gastric cancer than in intestinal-type disease [60]. However, in a multivariate analysis, the MVD status was not an independent prognostic factor and did not necessarily reveal any prognostic significance [58], although vascular invasion was an independent prognostic factor in the Cox proportional hazards model [61]. In the present study, we found that the MVD, as determined via CD34 staining, was not an independent prognostic factor in multivariate analysis. However, NOS III expression, which closely correlates with MVD, was an independent prognostic factor predicting poor survival. It is not clear why NOS III expression is superior to MVD as a prognostic factor. Interestingly, not all endothelial cells of tumorassociated vessels expressed NOS III, which was more prominently seen in the vessels surrounding but not infiltrating a tumor (data not shown). It is not clear whether the patterns of NOS III indicate the functional status of the tumor vascular system. Moreover, we found direct clinical evidence of a strong correlation between the expression of NOS III and the expression of Sp1, which has been demonstrated to be an independent prognostic factor [37]. This finding suggests that NOS III is a critical downstream target gene, as described previously [5,28-31]. Because aberrant expression of NOS III has been noted in certain tumor cells [3-5], it is highly probable that $\mathrm{Sp} 1$ activation leads to altered NOS III expression in tumors, including both tumor epithelial and endothelial cells. Further studies will be needed to determine whether abnormally activated Sp1 expression contributes directly to tumor angiogenesis and overall aggressive tumor biology via NOS III expression, and whether Sp1 represents a potentially useful molecular marker for selecting patients with a poor prognosis to receive more aggressive preoperative or adjuvant therapy in a clinical trial.

In summary, we found that the level of NOS III expression was directly correlated with the status of tumor MVD and Sp1 expression, both of which are closely related to the postoperative prognosis for gastric cancer. We further demonstrated that abnormal NOS III expression is a potential risk factor for poor prognosis and directly relates to gastric cancer angiogenesis and progression. Therefore, preoperative determination of the NOS III level may be useful in selecting the modal- ity and deciding on the extent of postoperative therapy. Further investigation of the molecular mechanism by which the NOS III signaling pathway regulates gastric cancer development and progression and whether this pathway is a therapeutic target for controlling gastric cancer growth and metastasis is warranted.

Acknowledgments We thank Judy King for expert help in the preparation of this manuscript and Don Norwood for editorial comments.

\section{References}

1. Ignarro LJ, Buga GM, Wood KS, Byrns RE, Chaudhuri G. Endothelium-derived relaxing factor produced and released from artery and vein is nitric oxide. Proc Natl Acad Sci USA 1987;84: 9265-9.

2. Moncada S, Palmer RM, Higgs EA. Nitric oxide: physiology, pathophysiology, and pharmacology. Pharmacol Rev 1991;43: 109-42.

3. Fleming I, Busse R. Molecular mechanisms involved in the regulation of the endothelial nitric oxide synthase. Am J Physiol Regul Integr Comp Physiol 2003;284:R1-12.

4. Li H, Wallerath T, Munzel T, Forstermann U. Regulation of endothelial-type NO synthase expression in pathophysiology and in response to drugs. Nitric Oxide 2002;7:149-64.

5. Wu KK. Regulation of endothelial nitric oxide synthase activity and gene expression. Ann NY Acad Sci 2002:962:122-30.

6. Shaul PW. Regulation of endothelial nitric oxide synthase: location, location, location. Annu Rev Physiol 2002;64:74974.

7. Couffinhal T, Silver M, Zheng LP, Kearney M, Witzenbichler B, Isner JM. Mouse model of angiogenesis. Am J Pathol 1998;152: 1667-79.

8. Lala PK, Orucevic A. Role of nitric oxide in tumor progression: lessons from experimental tumors. Cancer Metastasis Rev 1998;17:91-106.

9. Masaki I, Yonemitsu Y, Yamashita A, Sata S, Tanii M, Komori K, et al. Angiogenic gene therapy for experimental critical limb ischemia: acceleration of limb loss by overexpression of vascular endothelial growth factor 165 but not of fibroblast growth factor2. Circ Res 2002;90:966-73.

10. Ma L, Chow JY, Cho CH. Cigarette smoking delays ulcer healing: role of constitutive nitric oxide synthase in rat stomach. Am J Physiol 1999;276:G238-48.

11. Brzozowski T, Konturek SJ, Drozdowicz D, Dembinski A, Stachura J. Healing of chronic gastric ulcerations by L-arginine. Role of nitric oxide, prostaglandins, gastrin and polyamines. Digestion 1995;56:463-71.

12. Soini Y, Puhakka A, Kahlos K, Saily M, Paakko P, Koistinen P, et al. Endothelial nitric oxide synthase is strongly expressed in malignant mesothelioma but does not associate with vascular density or the expression of VEGF, FLK1 or FLT1. Histopathology 2001; 39:179-86.

13. Bouloumie A, Schini-Kerth VB, Busse R. Vascular endothelial growth factor up-regulates nitric oxide synthase expression in endothelial cells. Cardiovasc Res 1999;41:773-80.

14. Chinje EC, Stratford IJ. Role of nitric oxide in growth of solid tumours: a balancing act. Essays Biochem 1997;32:61-72.

15. Xie K, Huang S. Contribution of nitric oxide-mediated apoptosis to cancer metastasis inefficiency. Free Radic Biol Med 2003;34: 969-86.

16. Hussain SP, Hofseth LJ, Harris CC. Radical causes of cancer. Nat Rev Cancer 2003;3:276-85. 
17. Jadeski LC, Hum KO, Chakraborty C, Lala PK. Nitric oxide promotes murine mammary tumour growth and metastasis by stimulating tumour cell migration, invasiveness and angiogenesis. Int J Cancer 2000;86:30-9.

18. Martin JH, Begum S, Alalami O, Harrison A, Scott KW. Endothelial nitric oxide synthase: correlation with histologic grade, lymph node status and estrogen receptor expression in human breast cancer. Tumour Biol 2000;21:90-7.

19. Klotz T, Bloch W, Jacobs G, Niggemann S, Engelmann U, Addicks K. Immunolocalization of inducible and constitutive nitric oxide synthases in human bladder cancer. Urology 1999;54: 416-9.

20. Takahashi M, Fukuda K, Ohata T, Sugimura T, Wakabayashi K. Increased expression of inducible and endothelial constitutive nitric oxide synthases in rat colon tumors induced by azoxymethane. Cancer Res 1997;57:1233-7.

21. Chhatwal VJ, Ngoi SS, Chan ST, Chia YW, Moochhala SM. Aberrant expression of nitric oxide synthase in human polyps, neoplastic colonic mucosa and surrounding peritumoral normal mucosa. Carcinogenesis 1994;15:2081-5.

22. Iwata S, Nakagawa K, Harada H, Oka Y, Kumon Y, Sakaki S. Endothelial nitric oxide synthase expression in tumor vasculature is correlated with malignancy in human supratentorial astrocytic tumors. Neurosurgery 1999;45:24-8.

23. Nussler AK, Gansauge S, Gansauge F, Fischer U, Butzer U, Kremsner PG, et al. Overexpression of endothelium-derived nitric oxide synthase isoform 3 in the vasculature of human pancreatic tumor biopsies. Langenbecks Arch Surg 1998;383:474-80.

24. Koh E, Noh SH, Lee YD, Lee HY, Han JW, Lee HW, et al. Differential expression of nitric oxide synthase in human stomach cancer. Cancer Lett 1999;146:173-80.

25. Doi C, Noguchi Y, Marat D, Saito A, Fukuzawa K, Yoshikawa T, et al. Expression of nitric oxide synthase in gastric cancer. Cancer Lett 1999;144:161-7.

26. Colasanti M, Cavalieri E, Persichini T, Mollace V, Mariotto S, Suzuki H, et al. Bacterial lipopolysaccharide plus interferongamma elicit a very fast inhibition of a $\mathrm{Ca}^{2+}$-dependent nitric oxide synthase activity in human astrocytoma cells. J Biol Chem 1997;272:7582-5.

27. Geller DA, Billiar TR. Molecular biology of nitric oxide synthases. Cancer Metastasis Rev 1998;17:7-23.

28. Wariishi S, Miyahara K, Toda K, Ogoshi S, Doi Y, Ohnishi S, et al. A SP1 binding site in the GC-rich region is essential for a core promoter activity of the human endothelial nitric oxide synthase gene. Biochem Biophys Res Commun 1995;216:72935 .

29. Tang JL, Zembowicz A, Xu XM, Wu KK. Role of Sp1 in transcriptional activation of human nitric oxide synthase type III gene. Biochem Biophys Res Commun 1995;213:673-80.

30. Zhang R, Min W, Sessa WC. Functional analysis of the human endothelial nitric oxide synthase promoter. Sp1 and GATA factors are necessary for basal transcription in endothelial cells. J Biol Chem 1995;270:15320-6.

31. Marsden PA, Heng HH, Scherer SW, Stewart RJ, Hall AV, Shi $\mathrm{XM}$, et al. Structure and chromosomal localization of the human constitutive endothelial nitric oxide synthase gene. J Biol Chem 1993;268:17478-88.

32. Black AR, Black JD, Azizkhan-Clifford J. Sp1 and kruppel-like factor family of transcription factors in cell growth regulation and cancer. J Cell Physiol 2001;188:143-60.

33. Suske G. The Sp-family of transcription factors. Gene 1999;238: 291-300.

34. Abdelrahim M, Samudio I, Smith R 3rd, Burghardt R, Safe S. Small inhibitory RNA duplexes for Sp1 mRNA block basal and estrogen-induced gene expression and cell cycle progression in MCF-7 breast cancer cells. J Biol Chem 2002;277:28815-22.

35. Chen F, Zhang F, Rao J, Studzinski GP. Ectopic expression of truncated Sp1 transcription factor prolongs the S phase and reduces the growth rate. Anticancer Res 2000;20:661-7.
36. Kumar AP, Butler AP. Enhanced Sp1 DNA-binding activity in murine keratinocyte cell lines and epidermal tumors. Cancer Lett 1999;137:159-65.

37. Wang L, Wei D, Huang S, Peng Z, Le X, Wu TT, et al. Transcription factor $\mathrm{Sp} 1$ expression is a significant predictor of survival in human gastric cancer. Clin Cancer Res 2003;9:6371-80.

38. Shi Q, Le X, Abbruzzese JL, Peng Z, Qian CN, Tang H, et al. Constitutive Sp1 activity is essential for differential constitutive expression of vascular endothelial growth factor in human pancreatic adenocarcinoma. Cancer Res 2001;61:4143-54.

39. Tschugguel W, Schneeberger C, Unfried G, Czerwenka K, Weninger W, Mildner M, et al. Expression of inducible nitric oxide synthase in human breast cancer depends on tumor grade. Breast Cancer Res Treat 1999;56:145-51.

40. Lin Z, Chen S, Ye C, Zhu S. Nitric oxide synthase expression in human bladder cancer and its relation to angiogenesis. Urol Res 2003;31:232-5.

41. Shochina M, Fellig Y, Sughayer M, Pizov G, Vitner K, Podeh D, et al. Nitric oxide synthase immunoreactivity in human bladder carcinoma. Mol Pathol 2001;54:248-52.

42. Felley-Bosco E, Bender F, Quest AF. Caveolin-1-mediated posttranscriptional regulation of inducible nitric oxide synthase in human colon carcinoma cells. Biol Res 2002;35:169-76.

43. Broholm H, Rubin I, Kruse A, Braendstrup O, Schmidt K, Skriver EB, et al. Nitric oxide synthase expression and enzymatic activity in human brain tumors. Clin Neuropathol 2003;22:273-81.

44. Broholm H, Braendstrup O, Lauritzen M. Nitric oxide synthase expression of oligodendrogliomas. Clin Neuropathol 2001;20: 233-8.

45. Rajnakova A, Goh PM, Chan ST, Ngoi SS, Alponat A, Moochhala S. Expression of differential nitric oxide synthase isoforms in human normal gastric mucosa and gastric cancer tissue. Carcinogenesis 1997;18:1841-5.

46. Orucevic A, Bechberger J, Green AM, Shapiro RA, Billiar TR, Lala PK. Nitric oxide production by murine mammary adenocarcinoma cells promotes tumor-cell invasiveness. Int $\mathrm{J}$ Cancer 1999;81:889-96.

47. Liu R, Oberley TD, Oberley LW. Effects of endothelial nitric oxide synthase gene expression on the tumor biology of human oral carcinoma SCC-25 cells. Cell Growth Differ 1998;9:239-46.

48. Folkman J. What is the evidence that tumors are angiogenesis dependent? J Natl Cancer Inst 1990;82:4-6.

49. Weidner N, Semple JP, Welch WR, Folkman J. Tumor angiogenesis and metastasis - correlation in invasive breast carcinoma. N Engl J Med 1991;324:1-8.

50. Xie K. Interleukin-8 and human cancer biology. Cytokine Growth Factor Rev 2001;12:375-91.

51. Yoshikawa T, Tsuburaya A, Kobayashi O, Sairenji M, Motohashi $\mathrm{H}$, Yanoma S, et al. Plasma concentrations of VEGF and bFGF in patients with gastric carcinoma. Cancer Lett 2000;153:7-12.

52. Sier CF, Kubben FJ, Ganesh S, Heerding MM, Griffioen G, Hanemaaijer R, et al. Tissue levels of matrix metalloproteinases MMP-2 and MMP-9 are related to the overall survival of patients with gastric carcinoma. Br J Cancer 1996;74:413-7.

53. Brown LF, Berse B, Jackman RW, Tognazzi K, Manseau EJ, Senger DR, et al. Expression of vascular permeability factor (vascular endothelial growth factor) and its receptors in adenocarcinomas of the gastrointestinal tract. Cancer Res 1993;53:4727-35.

54. Guo YS, Beauchamp RD, Jin GF, Townsend CM Jr, Thompson JC. Insulinlike growth factor-binding protein modulates the growth response to insulinlike growth factor 1 by human gastric cancer cells. Gastroenterology 1993;104:15 951-604.

55. Du JR, Jiang Y, Zhang YM, Fu H. Vascular endothelial growth factor and microvascular density in esophageal and gastric carcinomas. World J Gastroenterol 2003;9:1604-6.

56. Takahashi R, Tanaka S, Kitadai Y, Sumii M, Yoshihara M, Haruma K, et al. Expression of vascular endothelial growth factor and angiogenesis in gastrointestinal stromal tumor of the stomach. Oncology 2003;64:266-74. 
57. Joo YE, Sohn YH, Joo SY, Lee WS, Min SW, Park CH, et al. The role of vascular endothelial growth factor (VEGF) and p53 status for angiogenesis in gastric cancer. Korean J Intern Med 2002;17: 211-9.

58. Lu M, Jiang Y, Wang R. The relationship of vascular endothelial growth factor and angiogenesis to the progression of gastric carcinoma. Zhonghua Bing Li Xue Za Zhi (Chin J Pathol) 1998;27:278-81.

59. Sanz-Ortega J, Steinberg SM, Moro E, Saez M, Lopez JA, Sierra E, et al. Comparative study of tumor angiogenesis and immuno- histochemistry for p53, c-ErbB2, c-myc and EGFr as prognostic factors in gastric cancer. Histol Histopathol 2000;15:455-62.

60. Tenderenda M, Rutkowski P, Jesionek-Kupnicka D, Kubiak R. Expression of CD34 in gastric cancer and its correlation with histology, stage, proliferation activity, p53 expression and apoptotic index. Pathol Oncol Res 2001;7:129-34.

61. Chen CN, Cheng YM, Lin MT, Hsieh FJ, Lee PH, Chang KJ. Association of color Doppler vascularity index and microvessel density with survival in patients with gastric cancer. Ann Surg 2002;235:512-8. 